\section{Practicing What You Preach}

\section{INTRODUCTION}

Objective: A survey was used to gauge the readiness of the participants both in theory prior to a course, following the course when they put their knowledge to use in an $\mathrm{MCl}$ (mass casualty incident) practical drill scenario.

Background: Putting to use what you are taught is no simple task. Students were given a survey to assess their readiness to manage an $\mathrm{MCl}$ prior to the seminar, and following an active $\mathrm{MCl}$ scene. Students partook in a seminar about $\mathrm{MCl}$ management, and following the seminar used their knowledge in $\mathrm{MCl}$ drill.

\section{METHODS}

Medical students attended the $\mathrm{MCl}$ workshop; among them, $73 \%$ of the students participated in both the training program and the practical session which they were the managers of $\mathrm{MCl}$ scenario. The group consisted of $0.6 \%$ males and the rest were female medical students. $60 \%$ of the participants had not ever been formerly trained for MCls while the others had undergone such training in the year prior to the current training program. The students were given a survey to assess their level of readiness prior to and following the training as well as following the use of their skills in the practical $\mathrm{MCl}$ secession.

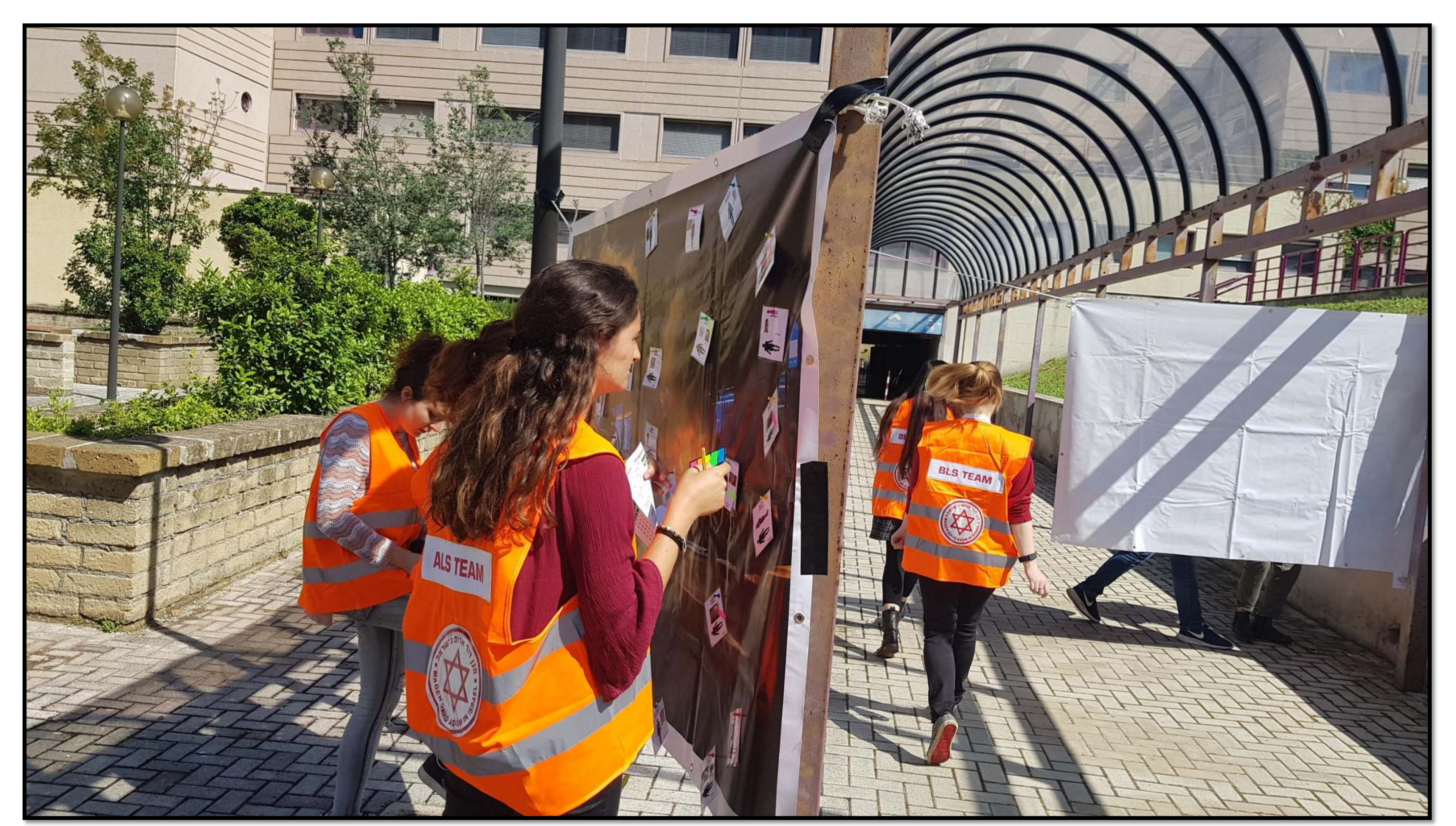

Figure 1: Scene management Drill

\section{Dr. Eli Jaffe}

Magen David Adom in Israel

Ben Gurion University of the Negev

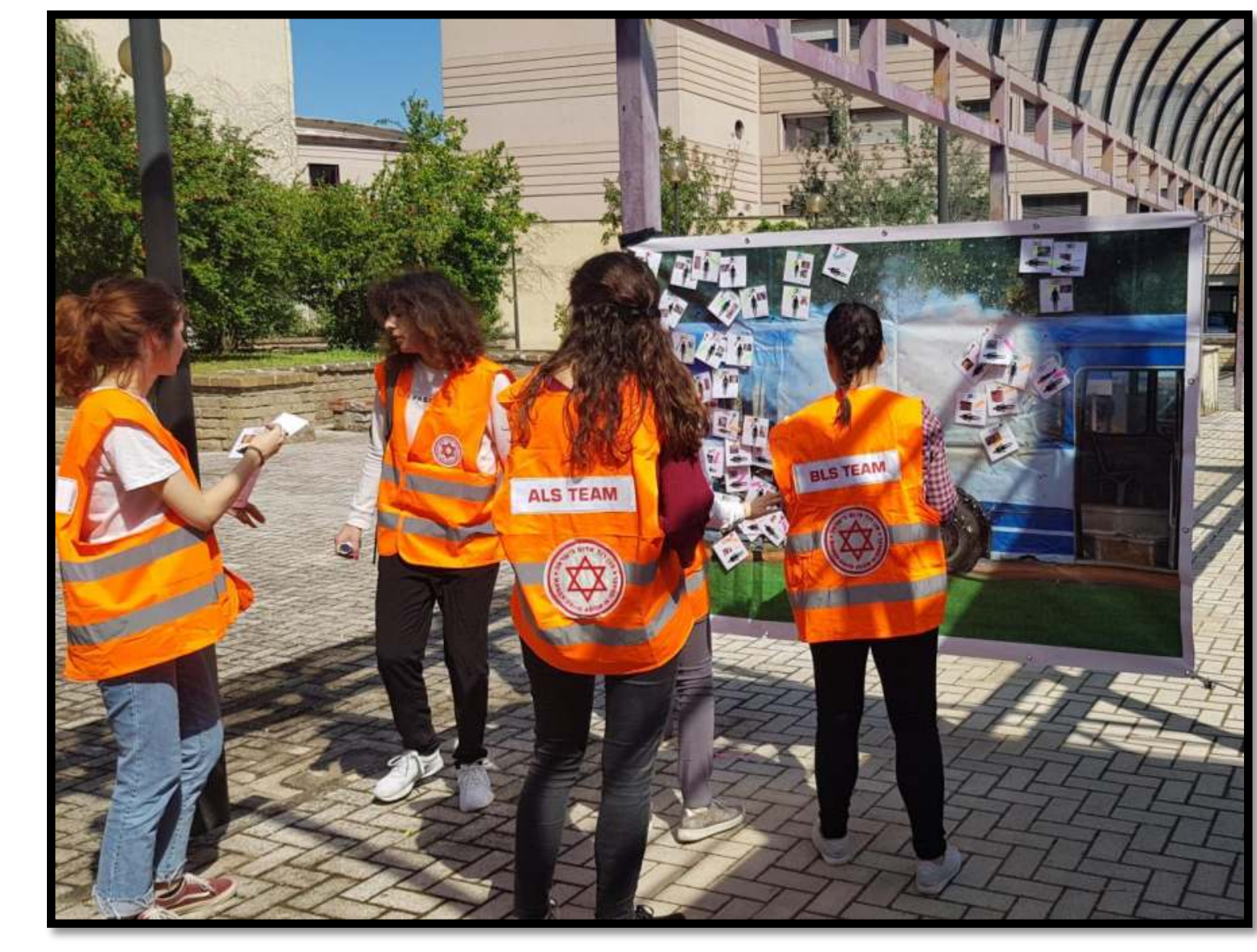

Figure 2: Triage Drill

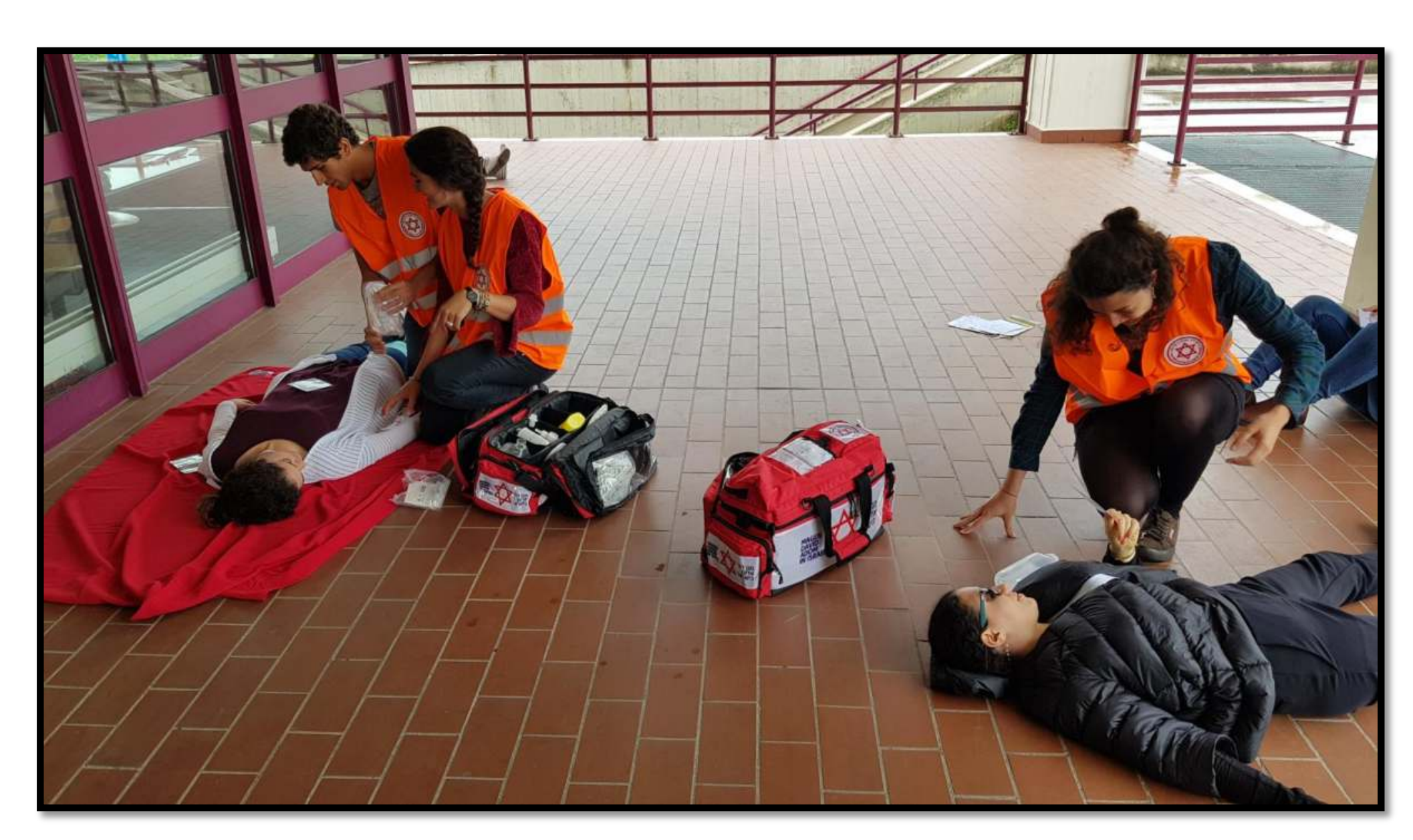

Figure 3: Practical Triage Drill

\section{RESULTS}

The mean level of self-efficacy prior to the $\mathrm{MCl}$ training $(M=3.43, S D+0.42)$ increased after the training $(M=3.71$, $S D+0.37)$ and remained at the same higher level $(M=3.71$, SD+0.51) after the medical students were exposed to the practical training. The overall difference between the mean self-efficacy scores in the three time frames was not found to be significant.

The mean level of confidence in managing $\mathrm{MCl}$ s prior to the training $(\mathrm{M}=2.83$; $\mathrm{SD}+0.89)$ increased after the training $(M=3.56 ; \quad S D+0.53)$ and remained higher following practical training, despite a slight decrease $(M=3.52$, $\mathrm{SD}+0.63)$.

\section{DISCUSSION}

The participants demonstrated a difference between the theoretical readiness, and the practical ability to apply their knowledge in real time situations. Further research needs to be done to determine and show the value of practical drills.
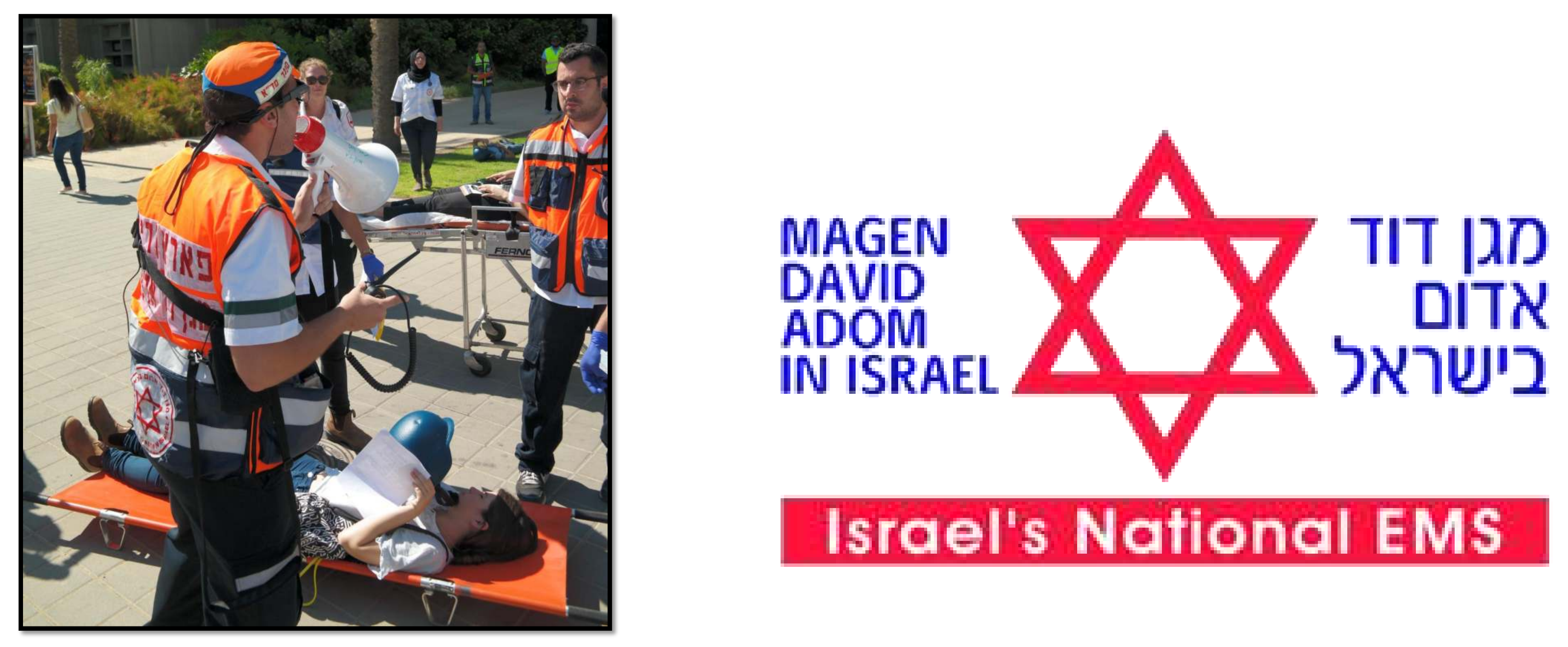

Figure :4 Scene management Practical Drill

\section{THANKS}

MDA's International Relations Department \& Instruction Division, Tor Vorgata University. 